\title{
A Conjugated Polymer Fluorescent Sensor for Continuous Identification of Copper(II) and Pyrophosphate in Blood Serum and Synovial Fluid
}

\author{
Mingming Guan, ${ }^{*}$ Chunling Xu, ${ }^{* *}$ Jiahua MA, ${ }^{* *}$ Ting YANG,* Jilin LIU,* and Guodong FenG $* \dagger$ \\ *Department of Analytical Chemistry, College of Chemistry, Jilin University, Jiefang 2519, Changchun \\ 130012, P. R. China \\ **Department of Ophthalmology, The Second Hospital of Jilin University, Changchun 130041, P. R. China \\ ***Engineering Research Center for Biomass Resource Utilizaiton and Modification of Sichuan Province, \\ Southwest University of Science and Technology, Mianyang 621010, P. R. China
}

\begin{abstract}
A novel "on-off-on" super-sensitive conjugated polymer fluorescence sensor (PPE-DPA) was developed and it was applied to realize the continuous recognition of $\mathrm{Cu}^{2+}$ and pyrophosphate (PPi). The fluorescence intensity decreased linearly with the change of $\mathrm{Cu}^{2+}$ from 0.05 to $5.0 \mu \mathrm{mol} \mathrm{L}{ }^{-1}$ and the limit of detection was $24 \mathrm{nmol} \mathrm{L}^{-1}$. The fluorescence intensity was linearly enhanced with the increase of PPi from 0.5 to $12.0 \mu \mathrm{mol} \mathrm{L}^{-1}$ and the limit of detection was $230 \mathrm{nmol} \mathrm{L}^{-1}$. In addition, this method was applied to detect PPi in the blood serum and synovial fluid of patients with arthritis and satisfactory results were obtained. Thus, the PPE-DPA is not only an effective tool for detecting $\mathrm{Cu}^{2+}$ and PPi in samples, but also presents a potential way to diagnose arthritis.
\end{abstract}

Keywords Conjugated polymer, fluorescence sensor, $\mathrm{Cu}^{2+}$, pyrophosphate, synovial fluid, blood serum

(Received December 30, 2018; Accepted January 24, 2019; Advance Publication Released Online by J-STAGE February 1, 2019)

\section{Introduction}

$\mathrm{Cu}^{2+}$ and pyrophosphate (PPi) are widely found in organisms and they play very important roles in life science, medicine and chemical processes. $\mathrm{Cu}^{2+}$, as the third most abundant transition metal ion after $\mathrm{Fe}^{3+}$ and $\mathrm{Zn}^{2+}$ in the human body, ${ }^{1}$ is involved in many critical physiological processes. Besides, many diseases could be caused by irregularities of $\mathrm{Cu}^{2+}$ in the human body. ${ }^{2-5}$ Similarly, as one of the most important biological anions, PPi is produced by hydrolysis of adenosine triphosphate (ATP) catalyzed by hydrolases, ${ }^{6}$ and participates in the replication of DNA, ${ }^{7}$ processing of genetic information ${ }^{8}$ and other bioenergetic and metabolic processes. ${ }^{9,10}$ But some diseases would be caused by abnormal concentrations of $\mathrm{PPi}$, such as calcium pyrophosphate dehydrate crystals, ${ }^{11}$ chondrocalcinosis, ${ }^{12}$ vascular calcification, ${ }^{13}$ kidney stones, ${ }^{14}$ arthritis, ${ }^{15}$ hypophosphatasis, ${ }^{16}$ medial arteriosclerosis ${ }^{17}$ and so on. And the level of intracellular PPi has become an important indicator in cancer and real-time DNA sequencing research. ${ }^{18}$ In addition, it is reported that the levels of PPi in synovial fluid is higher for patients with arthritis than normal, but the same is in serum. ${ }^{19,20}$ As such, PPi could be a potential biomarker for the treatment and clinical diagnosis of arthritis. ${ }^{12,21}$ In a word, selective identification and detection of $\mathrm{Cu}^{2+}$ and PPi are important for life science and disease diagnosis.

M. Guan and C. Xu contributed equally to this work.

$\uparrow$ To whom correspondence should be addressed.

E-mail: fenggd@jlu.edu.cn
In recent years, fluorescence probes for separate identification of $\mathrm{Cu}^{2+22-25}$ and $\mathrm{PPi}^{26,27}$ have been widely reported, and there are also some sensors for identifying PPi with DPA-M $\mathrm{M}^{\mathrm{n}+}$ as a chelate group. ${ }^{28,29}$ But sensors for continuous identification of $\mathrm{Cu}^{2+}$ and PPi are still rare. ${ }^{30}$ Obviously, for continuous identification sensors, the workload of the synthesis and the cost can be reduced, the operation is simpler and the efficiency is higher. Among all fluorescence probes, conjugated polymer (CP) fluorescence probes have a unique $\pi-\pi^{*}$ conjugated molecular wire structure, which makes it possible for local perturbation to be amplified and utilized in the whole polymer molecular chain or even in the whole polymer system, namely, the superquenching phenomenon. And, this property determines that $\mathrm{CP}$ probes have the ability to detect ultra-low content of substances to be measured, and show stronger sensitivity than small molecular fluorescence sensors. ${ }^{31,32}$ Our research focus was on how to use the advantage of $\mathrm{CP}$ to develop a fluorescence sensor for $\mathrm{Cu}^{2+}$ and PPi.

In our previous research works, carboxylate sodium or guanidinium side groups were modified to the side chain of $\mathrm{PPE}^{32,33}$ and it was found that these conjugated polymers were not responsive to copper ion. In this paper, a new "on-off-on" relay identification $\mathrm{CP}$ fluorescence sensor, poly(2,5-bis(4(bis(pyridin-2-ylmethyl)amino)butoxyl)-1,4-phenylethynylene1,4-poly(phenylene ethynylene)) (PPE-DPA), was synthesized successfully in consideration that DPA has a certain complexation effect on $\mathrm{Cu}^{2+}$. Based on the fluorescence "on-off-on" phenomenon, the continuous recognition of $\mathrm{Cu}^{2+}$ and PPi was realized. Through optimization experiments and titration experiments, we found that the detection of $\mathrm{Cu}^{2+}$ and PPi had 


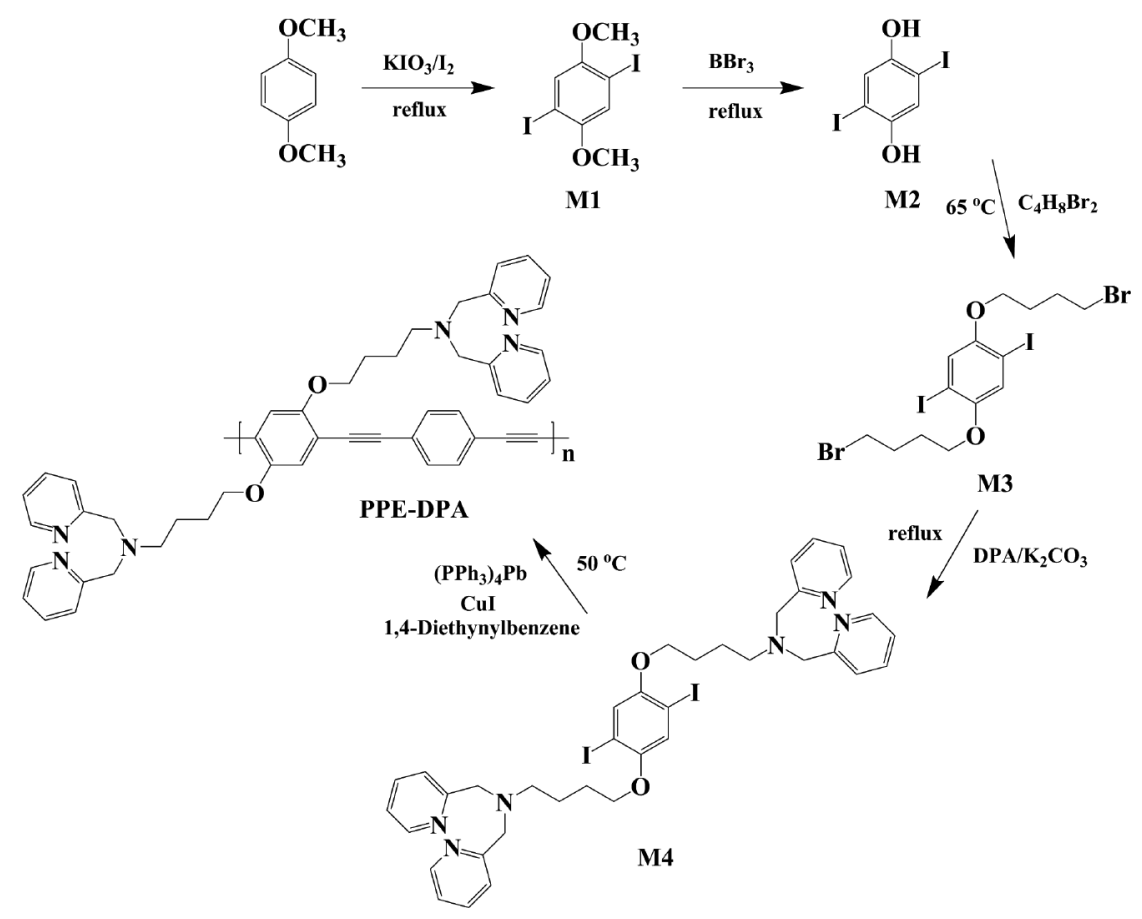

Scheme 1 Synthetic route of PPE-DPA.

good selectivity, high sensitivity, good linear range and low detection limit. Most importantly, the PPE-DPA has been successfully applied to detect PPi in blood serum and synovial fluid of patients with arthritis and the results were consistent with the previous literatures. ${ }^{16,34,35}$ Therefore, the PPE-DPA provides a new feasible method for the quantitative determination of PPi in synovial fluid and blood serum, thus offering a method for the diagnosis of arthritis.

\section{Experimental}

\section{Reagents and chemicals}

1,4-Diethynylbenzene (96\%) and $\left(\mathrm{PPh}_{3}\right)_{4} \mathrm{Pd}(99 \%)$ were purchased from J\&K SCIENTIFIC Ltd. (Beijing, China). $\mathrm{NaCl}$, $\mathrm{HCl}, \mathrm{NaOH}, \mathrm{K}_{2} \mathrm{CO}_{3}, \mathrm{Na}_{2} \mathrm{~S}_{2} \mathrm{O}_{3}, \mathrm{KH}_{2} \mathrm{PO}_{4}, \mathrm{Na}_{2} \mathrm{HPO}_{4} \cdot 12 \mathrm{H}_{2} \mathrm{O}$ and $\mathrm{NaH}_{2} \mathrm{PO}_{4} \cdot 2 \mathrm{H}_{2} \mathrm{O}, \mathrm{H}_{3} \mathrm{PO}_{4}, \mathrm{CH}_{3} \mathrm{COOH}$, sulfuric acid (98\%) and $\mathrm{H}_{3} \mathrm{BO}_{3}$ were purchased from Beijing Chemical Works (Beijing, China). 1,4-Dimethoxybenzene, iodine, potassium iodate, boron tribromide, 1,4-dibromobutane, CuI and DPA were purchased from Energy Chemical Technology Co., Ltd. (Shanghai, China). Triethylamine and diisopropylamine were purchased from Tianjin Fu Yu Chemical Co., Ltd. (Tianjin, China). Dichloromethane, methanol, ethanol, tetrahydrofuran, $\mathrm{N}, \mathrm{N}$ dimethylformamide, acetonitrile, acetone, ether, petroleum ether and acetic ether were purchased from Tianjin Tiantai Fine Chemical Co., Ltd. (Tianjin, China). The solutions of metal ions and anions were prepared from their salts, which were purchased from Beijing Chemical Reagent Corporation (Beijing, China). Moreover, the counter-anion of metal ion salts is generally $\mathrm{Cl}^{-}, \mathrm{SO}_{4}^{2-}$ or $\mathrm{NO}_{3}^{-}$, and the counter-cation of anion salts is generally $\mathrm{Na}^{+}$or $\mathrm{K}^{+}$. Anhydrous $\mathrm{MgSO}_{4}$ and $\mathrm{Na}_{2} \mathrm{SO}_{4}$ were purchased from Tianjin Dong Li Big Chemical Reagent Factory (Tianjin, China). Hepes was purchased from Promega Corporation. Tris was purchased from Sinopharm Chemical Reagent Co., Ltd. Thin layer chromatography (TLC) was carried out using silica gel 60 F254, and column chromatography was conducted over silica gel (300 - 400 mesh), both of which were obtained from Qingdao Ocean Chemicals (Qingdao, China). Twice-distilled water was used throughout all experiments. All chemicals were analytical reagent grade and were used without further treatment. For the practicality experiments, blood serum 1 , blood serum 2, synovial fluid 1 and synovial fluid 2 were obtained from in the second affiliated hospital of Jilin University in Changchun, China.

\section{Apparatus}

The nuclear magnetic resonance spectroscopy (NMR) of compounds were identified by ${ }^{1} \mathrm{H}$ NMR and ${ }^{13} \mathrm{C}$ NMR (Varian Mercury YH-400 NMR spectrometer), using tetramethylsilane (TMS) as an internal standard. ESI mass spectra were obtained using a Q-Trap 2000 (Applied Biosystems Corporation, USA) without using the liquid phase part. MOLDI-TOF mass spectra were obtained using a Autoflex speed TOF by Brucker. The average molecular weight and the molecular weight distribution was determined by GPC (Agilent 1260). All fluorescence measurements were carried out in a $1-\mathrm{cm}$ path length quartz cuvette with a Hitachi F-2700 spectrometer (Shimadzu Corporation, Japan). Measurements of fluorescence quantum yields were carried out with an FLS920 steady state and transient state fluorescence spectrometer (Edinburgh Instrument). All pH measurements were tested with a Sartorius PB-10 digital $\mathrm{pH}$ meter. All the optical measurements were carried out at room temperature $(298 \mathrm{~K})$ under ambient conditions.

\section{Synthesis of PPE-DPA}

PPE-DPA was synthesized by introducing di-(2-picolyl) amine (DPA) into the side chains of poly(phenylene) ethynylene (PPE), and the specific synthetic route consisting of 5 steps are shown in Scheme 1. The first step was to synthesize 1,4-diiodo-2,5dimethoxybenzene (M1) from 1,4-dimethoxybenzene with iodine and potassium iodate; then the second step was to remove the methyl group from the methoxy group of M1 to get 1,4-diiodo-2,5-dihydroxy- benzene (M2) with boron tribromide. 


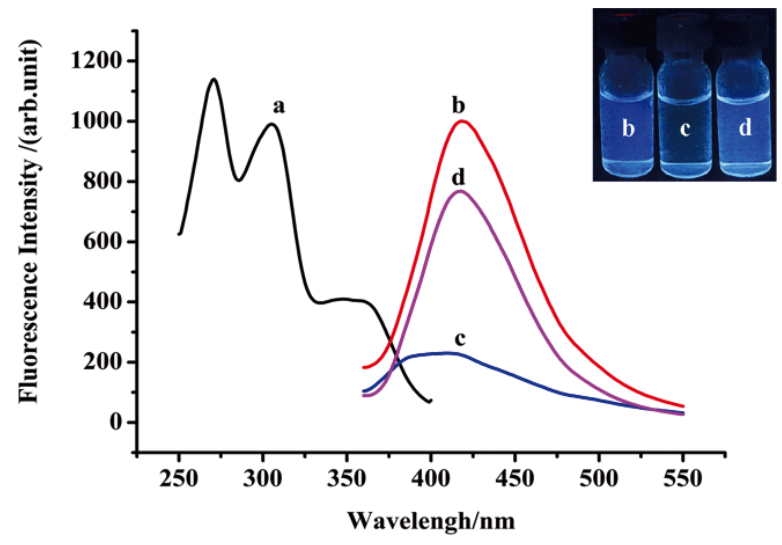

Fig. 1 (a) The fluorescence excitation spectrum of PPE-DPA; (b) the fluorescence emission spectrum and image of PPE-DPA; (c) the fluorescence emission spectrum and image of PPE-DPA-Cu${ }^{2+}$; (d) the fluorescence emission spectrum and image of PPE-DPA-Cu ${ }^{2+}-P P i$. Entrance slit, $5 \mathrm{~nm}$; exit slit, $5 \mathrm{~nm}$. These images were taken under a UV-lamp with a light wavelength of $365 \mathrm{~nm}$. Concentration of PPEDPA and $\mathrm{Cu}^{2+}, 5.0 \mu \mathrm{mol} \mathrm{L}^{-1}$; concentration of PPi, $12.0 \mu \mathrm{mol} \mathrm{L}^{-1}$.

Thirdly, the hydroxyl of M2 was halogenated with 1,4-dibromobutane to give 1,4-bis(4-bromobutoxy)-2,5diiodobenz-ene (M3). The fourth step was to turn M3 into a monomer of PPE-DPA (M4) through ammonolysis reaction with DPA. The last step was the Sonogashira-coupling reaction, namely, the PPE-DPA was obtained by polymerization of M4 and 1,4-diethynylbenzene (specific operations are shown in Supporting Information). As the GPC characterization showed, PPE-DPA featured an average molecular weight of 7230 (PDI = 1.120, about 9 repeat units). All syntheses were carried out under argon atmosphere.

\section{Experimental method}

A stock solution of PPE-DPA in DMSO was prepared with a concentration of $0.5 \mathrm{mmol} \mathrm{L}^{-1}$ and the concentration was calculated with respect to its monomer unit. The standard solutions of some metal ions, anions and PPi $\left(1.0 \mathrm{mmol} \mathrm{L}^{-1}\right)$ mentioned above were prepared with distilled water. When the stock solution of PPE-DPA was diluted to $5.0 \mu \mathrm{mol} \mathrm{L}-1$, a fluorescence emission peak was found at $420 \mathrm{~nm}$ upon excitation at $310 \mathrm{~nm}$. Then, $5.0 \mu \mathrm{mol} \mathrm{L}-1$ metal ion solution was added and fluorescence emission intensity was measured after the mixture reacted for $20 \mathrm{~min}$. Next, to the same solution above, was added $12.0 \mu \mathrm{mol} \mathrm{L}^{-1}$ solution of PPi, which also needed to react $20 \mathrm{~min}$, and then the fluorescence emission signal was recorded.

\section{Preparation of practical sample solutions}

First, the synovial fluid of arthritis patients and blood serum were purified by centrifugation to remove proteins that may affect the detection of PPi. After centrifugation, the synovial fluid and blood serum were diluted six times with Hepes buffer. Then the resulting solutions were referred to as the practical sample solutions.

\section{Results and Discussion}

\section{Spectral properties of PPE-DPA}

The excitation and emission spectra of PPE-DPA measured are shown in Figs. 1(a) and 1(b). The strong fluorescence

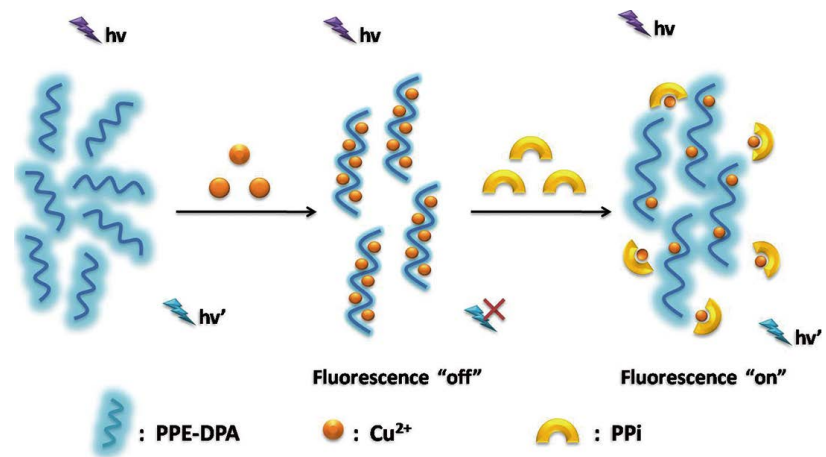

Fig. 2 Sensing mechanism of PPE-DPA.

emission peak at $420 \mathrm{~nm}$ was obtained when $310 \mathrm{~nm}$ was selected as the experimental excitation wavelength. In addition, it could be found that the strong fluorescence emission peak of PPE-DPA $\left(5.0 \mu \mathrm{mol} \mathrm{L}^{-1}\right)$ can be quenched to about $18 \%$ of the initial strength due to $\mathrm{Cu}^{2+}\left(5.0 \mu \mathrm{mol} \mathrm{L}^{-1}\right)$, Fig. 1(c). And it can be seen from Fig. 1(d) that the weak fluorescence emission peak increased to $70 \%$ of the original intensity by adding PPi solution $\left(12.0 \mu \mathrm{mol} \mathrm{L}^{-1}\right)$. Meanwhile, the fluorescence quantum yield of PPE-DPA $\left(5.0 \mu \mathrm{mol} \mathrm{L}^{-1}\right)$ was also measured. The absolute fluorescence quantum yield is $2.48 \%$. Based on this fluorescent "on-off-on" phenomenon, a novel fluorescent CP sensor with DPA for label-free detection of $\mathrm{Cu}^{2+}$ and its complex with $\mathrm{Cu}^{2+}$ for detecting PPi were studied.

The specific sensing mechanism is shown in Fig. 2. PPE acted as a fluorophore in this sensor and then its side chain was modified by DPA, which has the advantages of fast metal ion coordination rate, good biocompatibility, high selectivity and so on. The action of DPA with $\mathrm{Cu}^{2+}$ led to the photo-induced electron transfer (PET) process from the fluorophore to the $\mathrm{Cu}^{2+}$, showing the fluorescence quenching. ${ }^{36,37}$ The oxygen atoms on the P-O in PPi have strong coordination with $\mathrm{Cu}^{2+} .28$ The addition of PPi to the above system would compete with the PPE-DPA system in the binding of $\mathrm{Cu}^{2+}$, and then result in a partial recovery in the fluorescence intensity of PPE-DPA-Cu ${ }^{2+}$ by blocking the PET pathway. Therefore, this label-free fluorescence $\mathrm{CP}$ sensor can be used to continuously detect $\mathrm{Cu}^{2+}$ and PPi.

\section{Optimization of testing conditions}

In order to obtain a better as well as a more stable fluorescence phenomenon, conditions were explored, including solvent, $\mathrm{pH}$, buffer solution and time. Firstly, for conjugated polymers, because their stability may not be particularly good, there are many substances that may lead to aggregation and fluorescence self-quenching. As such, we need to find a stable condition for conjugated polymer sensors to play the greatest role. Therefore, the effect of organic solvents on the sensing performance of PPE-DPA was studied, including $\mathrm{CH}_{3} \mathrm{OH}, \mathrm{CH}_{3} \mathrm{CH}_{2} \mathrm{OH}, \mathrm{MeCN}$, THF, DMF and DMSO. Moreover, the effect of organic solvent content was also determined and the content ranged from $10 \%$ to 90\%. As shown in Figs. S7 and S8 (Supporting Information), it was found that PPE-DPA in the mixture of MeCN and Hepes buffer $(\mathrm{v} / \mathrm{v}=1 / 1)$ has the better fluorecence response to $\mathrm{Cu}^{2+}$. Secondly, we studied the effect of $\mathrm{pH}$ value from 3.0 to 12.0 on detection of $\mathrm{Cu}^{2+}$. As shown in Fig. S9 (Supporting Information), the degree of fluorescence quenching increased with the increase of $\mathrm{pH}$ from 3.0 to 8.0, which can be ascribed to the process of the tertiary amine part of PPE-DPA becoming quaternary 


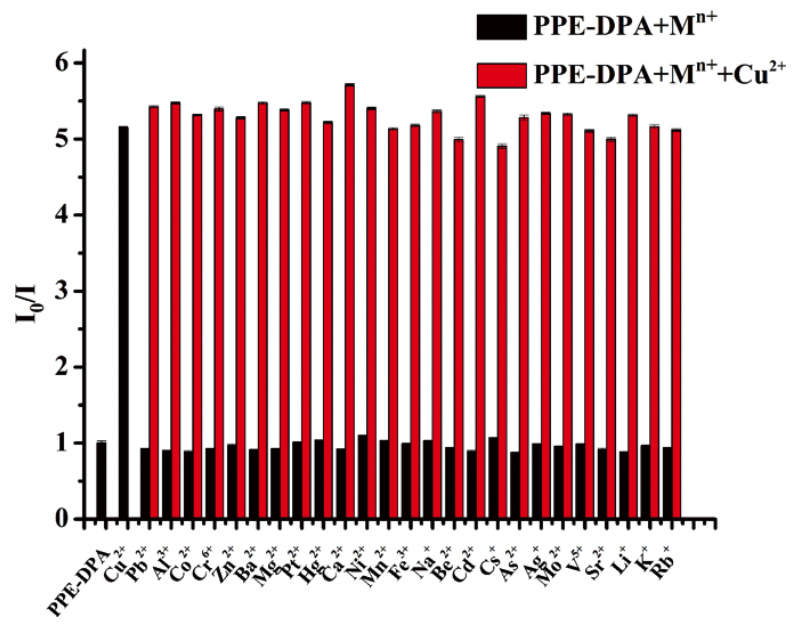

Fig. 3 The relative fluorescence intensities of PPE-DPA upon the addition of different metal ions (black bar); and the addition of $\mathrm{Cu}^{2+}$ in MeCN-Hepes buffer solution with other cations (red bar). $I_{0}$, Fluorescence intensity of PPE-DPA; $I$, fluorescence intensity of PPEDPA in the presence of different metal ions. Concentration of PPEDPA, $5.0 \mu \mathrm{mol} \mathrm{L}^{-1}$; concentration of metals, $5.0 \mu \mathrm{mol} \mathrm{L}^{-1}$.

ammonium salts at low $\mathrm{pH}$ levels so that they could not react with $\mathrm{Cu}^{2+}$. When $\mathrm{pH}=8.0$, the fluorescence quenching reached the maximum. From $\mathrm{pH}=8.0$ to $\mathrm{pH}=12.0$, the degree of fluorescence quenching gradually decreased because $\mathrm{Cu}^{2+}$ could be hydrolyzed under alkaline conditions. So, $\mathrm{pH}=8.0$ was chosen for the determination process. Meanwhile, the effect of several buffer systems $(\mathrm{pH}=8.0)$ were compared (Fig. S10, Supporting Information). And finally, Hepes buffer solution $\left(\mathrm{pH}=8.0\right.$ ) was chosen for PPE-DPA to detect $\mathrm{Cu}^{2+}$. Thirdly, the effect of reaction time of PPE-DPA with $\mathrm{Cu}^{2+}$ was studied. It was shown in Fig. S11 (Supporting Information) that the degree of fluorescence quenching gradually increased and the fluorescence was almost unchanged after $20 \mathrm{~min}$. In summary, the $\mathrm{MeCN} /$ Hepes buffer solution $\left(\mathrm{v} / \mathrm{v}=1 / 1 ; 1.0 \mathrm{mmol} \mathrm{L}^{-1}\right.$, $\mathrm{pH}=8.0$ ) of PPE-DPA was allowed to fully react for $20 \mathrm{~min}$ after adding $\mathrm{Cu}^{2+}$ before the fluorescence experiments were carried out.

\section{Metal ion sensing properties of PPE-DPA}

Experiments to determine the selectivity of PPE-DPA to various metal ions were carried out, and the concentrations of PPE-DPA and metal ions were all $5.0 \mu \mathrm{mol} \mathrm{L}^{-1}$. As shown in Fig. 3 (black bar), the relative fluorescence intensities of PPEDPA showed no obvious change in the presence of $\mathrm{Pb}^{2+}, \mathrm{Al}^{3+}$, $\mathrm{Co}^{2+}, \mathrm{Cr}^{6+}, \mathrm{Zn}^{2+}, \mathrm{Ba}^{2+}, \mathrm{Mg}^{2+}, \mathrm{Pt}^{2+}, \mathrm{Hg}^{2+}, \mathrm{Ca}^{2+}, \mathrm{Ni}^{2+}, \mathrm{Mn}^{2+}, \mathrm{Fe}^{3+}$, $\mathrm{Na}^{+}, \mathrm{Be}^{2+}, \mathrm{Cd}^{2+}, \mathrm{Cs}^{+}, \mathrm{As}^{2+}, \mathrm{Ag}^{+}, \mathrm{Mo}^{2+}, \mathrm{V}^{5+}, \mathrm{Sr}^{2+}, \mathrm{Li}^{+}, \mathrm{K}^{+}$and $\mathrm{Rb}^{+}$, but only $\mathrm{Cu}^{2+}$ could produce an obvious fluorescence quenching phenomenon. These results showed that PPE-DPA has good selectivity to $\mathrm{Cu}^{2+}$.

In order to further investigate the high selectivity of PPE-DPA to $\mathrm{Cu}^{2+}$, interference experiments of other metal ions were carried out. The tested results are illustrated in Fig. 3 (red bar) and it shows that these competing metal ions have no significant interference on the detection of $\mathrm{Cu}^{2+}$. In a word, PPE-DPA showed high selectivity and good anti-interference ability for the detection of $\mathrm{Cu}^{2+}$.

Spectral titration experiment of PPE-DPA for $\mathrm{Cu}^{2+}$ determination In order to obtain deeper insight into the response performance

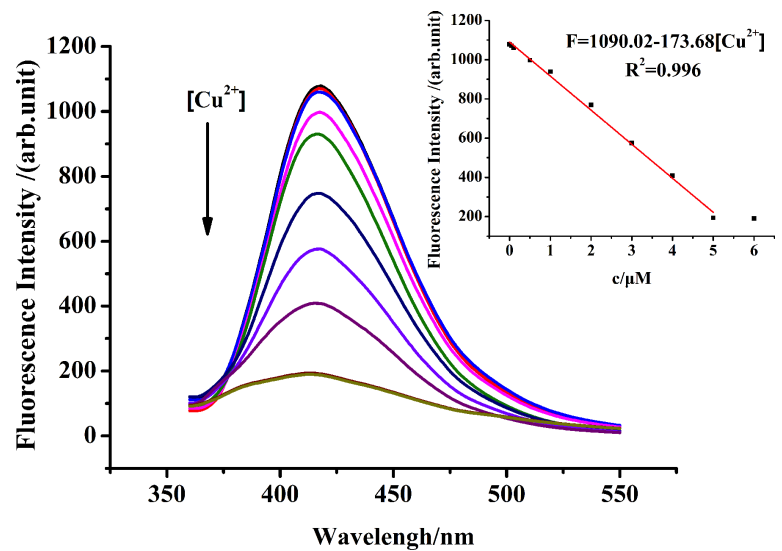

Fig. 4 Spectral titration curve of PPE-DPA for $\mathrm{Cu}^{2+}$ determination. Concentration of PPE-DPA, $5.0 \mu \mathrm{mol} \mathrm{L}{ }^{-1}$; concentration of $\mathrm{Cu}^{2+}, 0$, $0.05,0.1,0.5,1.0,2.0,3.0,4.0,5.0$ and $6.0 \mu \mathrm{mol} \mathrm{L}^{-1}$.

Table 1 Comparison of different methods for continuous detection of $\mathrm{M}^{\mathrm{n}+}$ and PPi

\begin{tabular}{|c|c|c|c|c|c|}
\hline \multirow[b]{2}{*}{$\begin{array}{l}\text { Fluorescent } \\
\text { sensor type }\end{array}$} & \multicolumn{2}{|c|}{$\mathrm{M}^{\mathrm{n}+}$} & \multicolumn{2}{|c|}{ PPi } & \multirow[b]{2}{*}{ Ref. } \\
\hline & $\begin{array}{l}\text { Range of } \\
\text { linearity/ } \\
\mu \mathrm{mol} \mathrm{L}-1\end{array}$ & $\begin{array}{c}\text { LOD/ } \\
\mathrm{nmol} \mathrm{L}^{-1}\end{array}$ & $\begin{array}{l}\text { Range of } \\
\text { linearity/ } \\
\mu \mathrm{mol} \mathrm{L}-1\end{array}$ & $\begin{array}{c}\text { LOD/ } \\
\mathrm{nmol} \mathrm{L}^{-1}\end{array}$ & \\
\hline Flavonoid derivative & $0-10$ & 100 & $0-20$ & 一 & 30 \\
\hline Chromene derivative & - & 1260 & $0-150$ & 2020 & 37 \\
\hline NTPA-Fe ${ }_{3} \mathrm{O}_{4} @ \mathrm{SiO}_{2}$ & $0-200$ & - & $0-200$ & 一 & 38 \\
\hline Gold nanorod & $0.15-2.5$ & 75 & $5-75$ & 820 & 39 \\
\hline Carbon dot & $0.5-11$ & 2 & $10-1700$ & 500 & 40 \\
\hline Polynorbornene & - & 204 & - & 28000 & 41 \\
\hline Conjugated polymer & $0-10$ & 一 & $5-16$ & 1000 & 42 \\
\hline $\begin{array}{l}\text { Conjugated } \\
\text { polyelectrolyte }\end{array}$ & - & 一 & $0-10$ & 340 & 43 \\
\hline PPE-DPA & $0.05-5$ & 24 & $0.5-12$ & 230 & This \\
\hline
\end{tabular}

of PPE-DPA to $\mathrm{Cu}^{2+}$, the spectral titration experiment was developed under the optimal conditions. Figure 4 shows the recorded fluorescent change of PPE-DPA $\left(5.0 \mu \mathrm{mol} \mathrm{L}^{-1}\right)$ in reaction to the addition of $\mathrm{Cu}^{2+}(0,0.05,0.1,0.5,1.0,2.0,3.0$, 4.0, 5.0 and $6.0 \mu \mathrm{mol} \mathrm{L}^{-1}$ ). The results show that the degree of fluorescence quenching increased with the increase of $\mathrm{Cu}^{2+}$ concentration. But, when the coordination reaction of DPA and copper ion reach equilibrium and the fluorescent emission intensity of PPE-DPA cannot be changed with the increase of copper ion concentration. There was a good linear relationship from 0.05 to $5.0 \mu \mathrm{mol} \mathrm{L} \mathrm{L}^{-1}$ and the square of the correlation coefficient was 0.996. The limit of detection (LOD) was $24 \mathrm{nmol} \mathrm{L}^{-1}$ (based on $S / N=3$ ). Compared with conventional methods $^{37-39}$ as illustrated in Table 1, PPE-DPA for $\mathrm{Cu}^{2+}$ detection offered a lower LOD and better linear range. Therefore, it can be seen from the above that PPE-DPA has high sensitivity to $\mathrm{Cu}^{2+}$.

Anion sensing properties of PPE-DPA-C $u^{2+}$ system

$\mathrm{PPi}$ can partially recover the fluorescence of PPE-DPA quenched by $\mathrm{Cu}^{2+}$. According to this phenomenon, the complexes of PPE-DPA with $\mathrm{Cu}^{2+}$ would be also used to detect PPi in this work. At first, selective experiments of the PPE- 


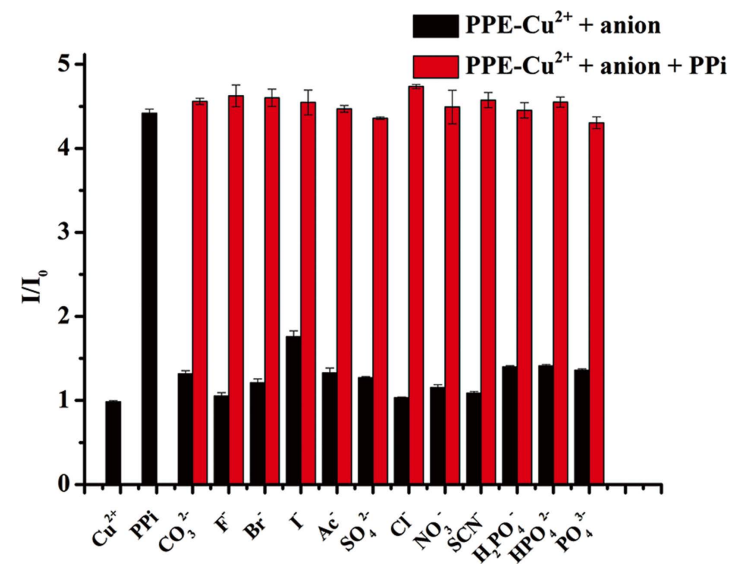

Fig. 5 The relative fluorescence intensities of the PPE-DPA-Cu ${ }^{2+}$ system upon adding different anions (black bar); and adding PPi separately in $\mathrm{MeCN}-\mathrm{Hepes}$ buffer solution with different interfering anions (red bar). $I_{0}$, Fluorescence intensity of PPE-DPA-Cu ${ }^{2+}$ system; $I$, fluorescence intensity of PPE-DPA-Cu ${ }^{2+}$ system in the presence of different anions. Concentration of PPE-DPA and $\mathrm{Cu}^{2+}, 5.0 \mu \mathrm{mol} \mathrm{L}{ }^{-1}$; concentration of anions, $12.0 \mu \mathrm{mol} \mathrm{L}^{-1}$.

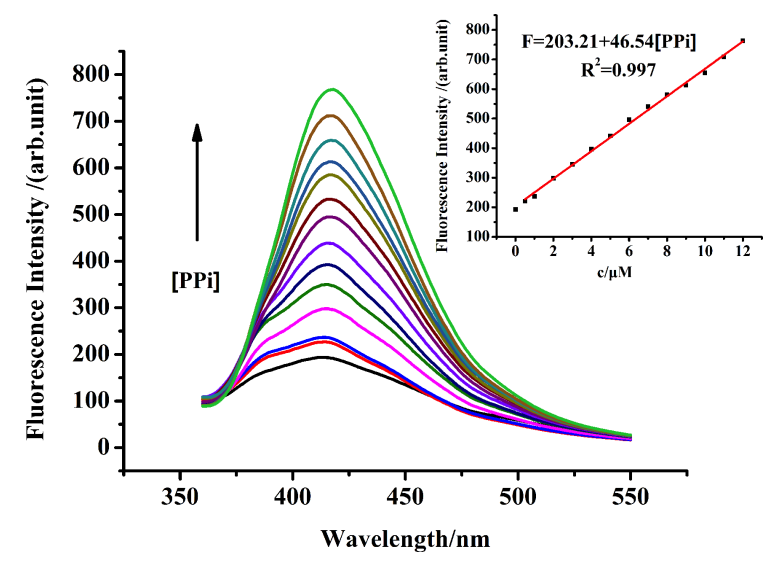

Fig. 6 Spectral titration curve of PPE-DPA-Cu ${ }^{2+}$ system for PPi determination. Concentration of PPE-DPA and $\mathrm{Cu}^{2+}, 5.0 \mu \mathrm{mol} \mathrm{L}{ }^{-1}$; concentration of anions, $0,0.5,1.0,2.0,3.0,4.0,5.0,6.0,7.0,8.0,9.0$, 10.0, 11.0, $12.0 \mu \mathrm{mol} \mathrm{L}-1$.

DPA- $\mathrm{Cu}^{2+}$ system to some common anions were considered, including $\mathrm{PPi}, \mathrm{CO}_{3}{ }^{2-}, \mathrm{F}^{-}, \mathrm{Br}^{-}, \mathrm{I}^{-}, \mathrm{Ac}^{-}, \mathrm{SO}_{4}{ }^{2-}, \mathrm{Cl}^{-}, \mathrm{NO}_{3}{ }^{-}, \mathrm{SCN}^{-}$, $\mathrm{H}_{2} \mathrm{PO}_{4}^{-}, \mathrm{HPO}_{4}{ }^{2-}$ and $\mathrm{PO}_{4}{ }^{3-}\left(12.0 \mu \mathrm{mol} \mathrm{L}{ }^{-1}\right)$. The results are shown in Fig. 5 (black bar) and indicate that only PPi could recover the fluorescence of PPE-DPA.

Furthermore, interference experiments were also carried out. The fluorescence intensity was detected after adding PPi to the mixture of PPE-DPA-Cu ${ }^{2+}$ and another anion. From Fig. 5 (red bar), it indicated that other anions have no obvious interference on the detection of PPi. In other words, the PPE-DPA- $\mathrm{Cu}^{2+}$ system has good selectivity and anti-interference ability for the detection of PPi.

\section{Spectral titration experiment of PPE-DPA-Cu ${ }^{2+}$ system for PPi} determination

In this part, we discuss the PPi titration experiment. Different concentrations of PPi $(0,0.5,1.0,2.0,3.0,4.0,5.0,6.0,7.0,8.0$, 9.0, 10.0, 11.0, $\left.12.0 \mu \mathrm{mol} \mathrm{L}^{-1}\right)$ were added to the PPE-DPA-
Table 2 Results of PPi detection in serum and synovial fluid

\begin{tabular}{crrrrc}
\hline \multirow{2}{*}{ Sample } & \multicolumn{5}{c}{ PPi added/ PPi found/ } \\
& $\mu \mathrm{mol} \mathrm{L}^{-1}$ & $\mu \mathrm{mol} \mathrm{L}$ & Recovy, RSD, & Ref. \\
\hline Blood serum 1 & 0.0 & 6.4 & - & - & $6.1 \pm 1.4^{33}$ \\
& 5.0 & 11.3 & 98.2 & 1.56 & - \\
Blood serum 2 & 10.0 & 16.5 & 101.2 & 1.67 & - \\
& 0.0 & 6.0 & - & - & $6.1 \pm 1.4^{33}$ \\
& 5.0 & 11.1 & 102.0 & 1.44 & - \\
Synovial fluid 1 & 10.0 & 15.9 & 98.8 & 1.21 & - \\
& 0.0 & 21.1 & - & - & $23.5 \pm 5.3^{16,34}$ \\
& 5.0 & 26.3 & 104.0 & 1.37 & - \\
Synovial fluid 2 & 10.0 & 30.8 & 97.1 & 1.54 & - \\
& 0.0 & 23.2 & - & - & $23.5 \pm 5.3^{16,34}$ \\
& 5.0 & 28.1 & 97.9 & 1.49 & - \\
\hline
\end{tabular}

Table 3 Comparison of conventional analytical methods for PPi in blood serum and synovial fluid

\begin{tabular}{lcc}
\hline \multirow{2}{*}{ Analytical method } & \multicolumn{2}{c}{$\mathrm{PPi} / \mu \mathrm{mol} \mathrm{L}{ }^{-1}$} \\
\cline { 2 - 3 } & Blood serum & Synovial fluid \\
\hline Enzymatic analytical method & 4.6 & 23.9 \\
P $^{32}$ chromatographic method & 4.4 & 22.7 \\
Colorimetric method & - & 23.5 \\
PPE-DPA-Cu ${ }^{2+}$ & 6.4 & 23.2 \\
\hline
\end{tabular}

$\mathrm{Cu}^{2+}$ system and the fluorescence was measured and recorded in Fig. 6. It shows that the fluorescence gradually recovered with increasing PPi concentration and there was a good linear relationship in the range from 0.5 to $12.0 \mu \mathrm{mol} \mathrm{L}^{-1}$ with square of correlation coefficient of $0.997\left(R^{2}=0.997\right)$. The limit of detection (LOD) was $230 \mathrm{nmol} \mathrm{L}^{-1}$ (based on $S / N=3$ ). Compared with other previous sensors, ${ }^{30,38-44}$ shown in Table 1, the PPE-DPA-Cu ${ }^{2+}$ system still offers obvious improvements in terms of linear detection and lower detection limit. Therefore, as a highly sensitive and selective fluorescent sensor, PPE-DPA$\mathrm{Cu}^{2+}$ could be used for the detection of PPi in real samples.

Analysis of PPi in blood serum and synovial fluid

In order to test the reliability of this method, we applied the PPE-DPA- $\mathrm{Cu}^{2+}$ system to detect PPi in the prepared synovial fluid and blood serum. The initial contents of PPi in blood serum and synovial fluid of arthritis patients using PPE-DPA$\mathrm{Cu}^{2+}$ as a fluorescent sensor are listed in Table 2, which was consistent with the values reported in past literature. ${ }^{16,34,35}$ And the recovery experiments for varying added amounts of PPi were carried out. The results are summarized in Table 2. The recovery of PPi ranged from 97.1 to $104.0 \%$ and the RSD was less than $1.67 \%$. In addition, we compared PPE-DPA-Cu ${ }^{2+}$ with conventional PPi analytical methods for the same sample, and the results are shown in Table 3. These results showed that the PPE-DPA- $\mathrm{Cu}^{2+}$ system provided a useful method for the detection of PPi in synovial fluid and blood serum of patients with arthritis.

\section{Conclusions}

In conclusion, a novel "on-off-on" conjugated polymer fluorescence sensor PPE-DPA was synthesized, which showed 
good selectivity and high sensitivity for continuous detection of $\mathrm{Cu}^{2+}$ and PPi. Fluorescence intensity of PPE-DPA decreased linearly with the change of $\mathrm{Cu}^{2+}$ concentration from 0.05 to $5.0 \mu \mathrm{mol} \mathrm{L}{ }^{-1}$ and the limit of detection (LOD) was $24 \mathrm{nmol} \mathrm{L}^{-1}$ (based on $S / N=3$ ). Similarly, the fluorescence intensity of PPE-DPA recovered linearly with the addition of PPi from 0.5 to $12.0 \mu \mathrm{mol} \mathrm{L}^{-1}$ and the limit of detection (LOD) was $230 \mathrm{nmol} \mathrm{L}^{-1}$ (based on $S / N=3$ ). Besides, the PPE-DPA-Cu ${ }^{2+}$ system was also successfully applied to detect PPi in blood serum and synovial fluid of arthritic patients. The results showed that the fluorescence sensor can be used to qualitatively and quantitatively detect PPi for early diagnosis of arthritic patients. Therefore, this work not only developed a highly selective and sensitive fluorescent sensor based on conjugated polymer for $\mathrm{Cu}^{2+}$ and $\mathrm{PPi}$, but also offered a new feasible method for the clinical diagnosis of arthritis.

\section{Acknowledgements}

This work was supported by the State Major Project for Science and Technology Development, China (No. 2013YQ470781023 ), the Science-Technology Development Project of Jilin Province of China (No. 20150204060GX), the Natural Science Foundation of Jilin Province (No. 20160101314JC).

\section{Supporting Information}

The Supporting Information provides the synthesis and characterization data of the intermediate and final product and supplementary spectral data (PDF). This material is available free of charge on the Web at http://www.jsac.or.jp/analsci/.

\section{References}

1. P. Y. Zhang, L. M. Pei, Y. Chen, W. C. Xu, Q. T. Lin, J. Q. Wang, J. H. Wu, Y. Shen, L. N. Ji, and H. Chao, Chem. Eur. J., 2013, 19, 15494.

2. Y. Zhang, X. Zeng, L. Mu, Y. Chen, J. X. Zhang, C. Redshaw, and G. Wei, Sens. Actuators, B, 2014, 204, 24.

3. Y. M. Liu, Q. Fei, H. Y. Shan, M. H. Cui, Q. Liu, G. D. Feng, and Y. F. Huan, Analyst, 2014, 139, 1868.

4. C. Wang, L. Lu, W. Ye, O. Zheng, B. Qiu, Z. Lin, L. Guo, and G. Chen, Analyst, 2014, 139, 656.

5. M. Yang, W. Meng, X. Liu, N. Su, J. Zhou, and B. Yang, RSC Adv., 2014, 4, 22288.

6. B. M. Long, F. M. Pfeffer, and C. J. Barrow, Sens. Actuators, $B, 2017,243,761$.

7. T. M. Fu, C. Y. Wu, C. C. Cheng, C. R. Yang, and Y. P. Yen, Sens. Actuators, B, 2000, 146, 171.

8. Q. C. Xu, C. Jin, X. H. Zhu, and G. W. Xing, Chin. J. Org. Chem., 2014, 34, 647.

9. S. Kim, M. S. Eom, S. K. Kim, S. H. Seo, and M. S. Han, Chem. Commun., 2013, 49, 152.

10. H. N. Lee, Z. Xu, S. K. Kim, K. M. Swamy, Y. Kim, S. J. Kim, and J. Y. Yoon, J. Am. Chem. Soc., 2007, 129, 3828.

11. D. J. McCarty, S. D. Solomon, M. L. Warnock, and E. Paloyan, J. Lab. Clin. Med., 2016, 78, 216.

12. M. Doherty, C. Becher, M. Regan, A. Jones, and J. Ledingham, Ann. Rheum. Dis., 1996, 55, 432.

13. W. C. O'Neill, M. K. Sigrist, and C. W. McIntyre, Nephrol., Dial., Transplant., 2010, 25, 187.

14. J. G. March, B. M. Simonet, and F. Grases, Clin. Chim.
Acta, 2001, 314, 187.

15. A. Caswell, D. F. Guilland-Cumming, P. R. Hearn, M. K. B. McGuire, and R. G. G. Russell, Ann. Rheum. Dis., 1983, 42, 27.

16. J. Deng, P. Yu, L. Yang, and L. Mao, Anal. Chem., 2013, 85, 2516.

17. A. E. Timms, Y. Zhang, R. G. G. Russell, and M. A. Brown, Rheumatology, 2002, 41, 725.

18. S. Xu, M. He, H. Yu, X. Cai, X. Tan, B. Lu, and B. Shu, Anal. Biochem., 2001, 299, 188.

19. A. M. Ho, M. D. Johnson, and D. M. Kingsley, Science, 2000, 289, 265.

20. M. Pattrick, E. Hamilton, J. Hornby, and M. Doherty, Ann. Rheum. Dis., 1991, 50, 214.

21. R. A. Terkeltaub, Am. J. Physiol.: Cell Physiol., 2001, 281, C1.

22. M. H. Lee, Y. H. Lee, J. H. Jung, Y. C. Park, Y. Kim, J. H. Lee, and J. S. Kim, Bull. Korean Chem. Soc., 2008, 29, 2033.

23. K. H. Jung, E. T. Oh, H. J. Park, and K. H. Lee, Biosens. Bioelectron., 2016, 85, 437.

24. P. Li, X. Duan, Z. Chen, Y. Liu, T. Xie, L. Fang, X. Li, M. Yin, and B. Tang, Chem. Commun., 2011, 47, 7755.

25. Z. Xu, J. Yoon, and D. R. Spring, Chem. Commun., 2010, 46, 2563.

26. W. Yu, J. Qiang, J. Yin, S. Kambam, F. Wang, Y. Wang, and X. Chen, Org. Lett., 2014, 16, 2220.

27. Z. Xu, J. Y. Choi, and J. Yoon, Bull. Korean Chem. Soc., 2011, 32, 1371.

28. D. H. Lee, J. H. Im, S. U. Son, Y. K. Chung, and J. I. Hong, J. Am. Chem. Soc., 2003, 125, 7752.

29. H. N. Lee, K. M. K. Swamy, S. K. Kim, J. Y. Kwon, Y. Kim, S. J. Kim, Y. J. Yoon, and J. Yoon, Org. Lett., 2007, 9, 243.

30. C. Zhao, B. Liu, X. Bi, D. Liu, C. Pan, L. Wang, and Y. Pang, Sens. Actuators, B, 2016, 229, 131.

31. H. Y. Mi, M. M. Guan, J. L. Liu, H. Y. Shan, Q. Fei, Y. F. Huan, and G. D. Feng, Spectrochim. Acta, Part A, 2017, 176, 168.

32. H. Y. Mi, M. M. Guan, H. Y. Shan, Q. Fei, Y. F. Huan, Z. Q. Zhang, and G. D. Feng, Anal. Sci., 2016, 32, 1039.

33. H. Y. Mi, J. L. Liu, M. M. Guan, Q. W. Liu, Z. Q. Zhang, and G. D. Feng, Talanta, 2018, 187, 314.

34. G. Lust and J. E. Seegmiller, Clin. Chim. Acta, 1976, 66, 241.

35. L. Tong, Z. Chen, Z. Jiang, M. Sun, L. Li, J. Liu, and B. Tang, Biosens. Bioelectron., 2015, 72, 51.

36. H. J. Kim, J. H. Lee, and J. I. Hong, Tetrahedron Lett., 2011, 52, 4944.

37. H. G. Lee, J. H. Lee, S. P. Jang, H. M. Park, S. J. Kim, Y. Kim, C. Kim, and R. G. Harrison, Tetrahedron, 2011, 67, 8073.

38. W. Zhu, X. Huang, Z. Guo, X. Wu, and H. Yu, H. Tian, Chem. Commun., 2012, 48, 1784.

39. X. Tian, Z. Dong, J. Hou, R. Wang, and J. Ma, J. Lumin., 2014, 145, 459.

40. L. Wang, Q. Song, Q. Liu, D. He, and J. Ouyang, Adv. Funct. Mater, 2015, 25, 7017.

41. Q. Wang, S. Zhang, H. Ge, G. Tian, N. Cao, and Y. Li, Sens. Actuators, B, 2015, 207, 25.

42. P. Yao, Z. Liu, J. Ge, Y Chen, and Q. Cao, Dalton Trans., 2015, 44, 7470 .

43. Y. Bao, H. Wang, Q. Li, B. Liu, Q. Li, W. Bai, B. Jin, and R. Bai, Macromolecules, 2012, 45, 3394.

44. X. Zhao and K. Schanze, Chem. Commun., 2010, 46, 6075. 